\title{
La historia del Arte en España. Devenir, discursos y propuestas
}

FICHA BIBLIOGRÁFICA

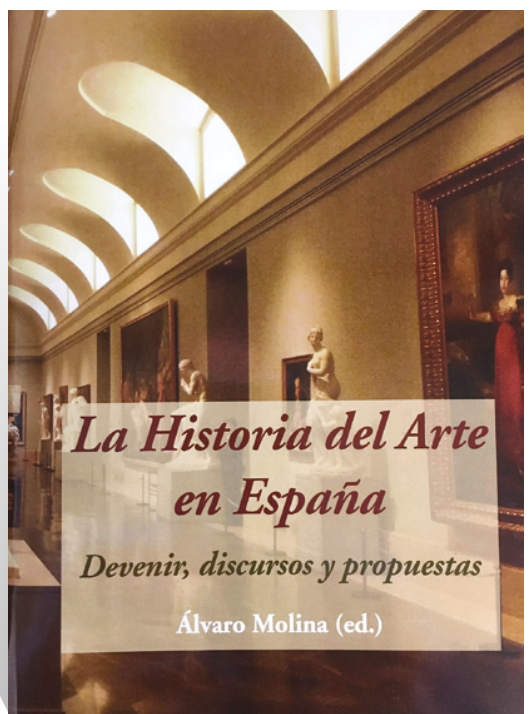

ÁlVARO MOLINA (ed.), La Historia del Arte en España. Devenir; discursos y propuestas, Madrid, Ediciones Polifemo, 2016, 557 págs, ISBN: 978-8416335-24-4

\section{José Luis De La Nuez Santana Universidad Carlos III de Madrid}

CONSIDERAMOS ESTE LIBRo como una interesante y ambiciosa propuesta de un grupo de investigadores que afrontan la compleja historiografía del arte en España a través de análisis de una gran variedad. En este sentido, caben tanto las visiones generales que estudian periodos amplios de la historia del arte en nuestro país con el fin de ir desvelando los sucesivos planteamientos metodológicos e interpretaciones que se han suscitado en el tiempo (Jesusa Vega y Javier Portús), como las que se detienen en momentos concretos de ese pasado, como es el medieval (Juan Carlos Ruiz Souza), el siglo XVIII (Álvaro Molina) o el XIX (Isabel Tejada), 
si bien este último se entiende desde un enfoque claramente museográfico. Más específicos son los capítulos que atienden al mundo contemporáneo, como el estudiado por Carmen Bernárdez sobre la materialidad; además, también encontramos una aproximación que se nos antoja muy necesaria a la historia de la fotografía en España (María Rosón), así como dos sugestivos estudios sobre la realidad del arte español del siglo XX, en un caso centrado en la producción crítica de Valeriano Bozal y José María Moreno Galván (Noemí Haro) y en el otro, clarificando el proyecto «Desacuerdos» y su singularidad en el panorama artístico español finisecular (Iñaki Estella). Por su parte, Isabel Cervera profundiza en la especial contribución de la historiografía española al conocimiento del arte asiático.

Por lo que se refiere a lo que podemos entender como una mirada en perspectiva sobre el significado de la historia del arte en España y la problemática de la diversidad de sus interpretaciones, cabe destacar en primer lugar el largo estudio de Jesusa Vega, que se propone una clarificación de la principales aportaciones de esta disciplina en nuestro país desde el siglo XVIII, atendiendo a una contextualización cultural y política. Vega señala que si bien es cierto que la historia del arte en España pasa por fases cuya orientación metodológica es compartida por otras escuelas historiográficas europeas, como ocurre con el formalismo, el atribucionismo o, más tarde, el marxismo, etc., no menos es que algunos rasgos la particularizan claramente. Por un lado, la persistencia de una visión profundamente nacionalista que llevó a algunos autores a hablar, como señala la autora, de una «veta brava» del arte español; por otro, las singularidades de nuestra historia, las dificultades de un cierto subdesarrollo cultural, el retraso con que se conforma el mundo académico de la historia del arte, y, finalmente, el baldón de los casi cuarenta años del franquismo, muy determinantes en la definición de una visión histórico-artística, con protagonistas dentro y fuera del territorio peninsular. Con todo, queda el interesante relato de las principales aportaciones de autores e instituciones que, pese a las dificultades, han ido creando la historia del arte que hoy conocemos. Desde luego, el balance no puede ser más que positivo, pues, como se señala en este capítulo, muchas de las figuras que han ido conformando este relato histórico (sin olvidar a los hispanistas) pueden perfectamente equipararse con aquellas que han construido la historia del arte europeo. Finalmente, al tratar las últimas décadas del siglo XX la autora no solamente señala los momentos claves en los que determinados autores (Gállego, Bozal, Marchán...) imprimen un giro fundamental para abrir paso a una historia del arte renovada en muchos sentidos; también se interesa por los cambios que han acaecido en la enseñanza de la historia del arte y su situación actual, en un momento en el que se extiende el peligro de la invisibilidad de esta disciplina.

Por su parte, Javier Portús, en su texto sobre la definición y redefinición de la «escuela española» de pintura, incide en un tema ya tratado por él con anterioridad que puede considerarse como su principal contribución al debate sobre la significación de la historiografía del arte en España. En torno a la escuela barroca española, Goya y el Greco, como figuras excéntricas a la primera pero también fundamentales, se crea la idea de un arte español que se inicia con Jovellanos y se consolida con Ceán Bermúdez y autores posteriores. No obstante, tiene bien cuidado el autor en señalar la importancia de las disidencias que se generan en relación con ese relato, que conserva bastante fuerza aún en el siglo XX. En este sentido, cabe resaltar la revisión del concepto de realismo impulsada entre otros por Julián Gállego y su 
estudio sobre la simbología barroca, así como también las posturas antiesencialista sobre este tema que mostraron autores como Lafuente Ferrari.

Se adentra Juan Carlos Ruiz Souza en la polémica historiográfica suscitada en torno al arte medieval español y su convivencia con el legado musulmán. A este respecto, más allá del cuestionamiento de la existencia de un arte mozárabe, polémica aireada en su momento por Camón Aznar y Bango Torviso, lo que le interesa especialmente a este autor es cuestionar las convenciones establecidas sobre un concepto tan caro a nuestra historiografía como es el de arte mudéjar, cuya especificidad se replantea aquí desde el momento en que se considera la influencia musulmana como un fenómeno con un grado de influencia de tal calado que va más allá de la particular contribución que se atribuye a una comunidad concreta, diferenciada por su cultura y tradición en el contexto de la sociedad cristiana.

Brillante nos resulta la aportación de la profesora Carmen Bernárdez sobre la importancia de la materialidad en el arte contemporáneo, un tema cuyo abordaje supera los conocidos análisis sobre las técnicas artísticas y su importancia en el arte del siglo XX. Bernárdez cree que interesarse por los materiales artísticos y su significación cultural supone entender la historia del arte desde una perspectiva muy distinta; esto es, siguiendo a Burke, se trataría de una «historia desde abajo», como puede ser también la historia del mundo cotidiano, por ejemplo. Lo cierto es que el análisis de la materialidad nos abre nuevas dimensiones interpretativas, incluso el replanteamiento de la historia del arte como disciplina convencional. Como señala la autora cuando destaca la aportación de la artista y filósofa Florence de Mèredieu, uno de los grandes retos para los historiadores del arte está precisamente en la búsqueda de una nueva conceptualización en torno a este tema, que se ha ido enriqueciendo a medida que la evolución del arte contemporáneo así lo ha permitido. Algunas de las propuestas metodológicas que se apuntan en este texto con oportuna precisión, como son la neuroestética de Semir Zeki o el neo-materialismo europeo y estadounidense, dan una idea de las posibilidades que permiten estos estudios.

Que las propuestas historiográficas sobre el arte asiático se han visto condicionadas por la visión eurocéntrica imperante en gran parte del siglo XX en España es una realidad que no duda en reconocer Isabel Cervera en su aproximación a esta cuestión. También destaca esta autora la inicial dependencia de la visión francesa, como puede apreciarse en las contribuciones de Jean Roger Riviere, uno de los primeros impulsores de esta temática en España. Cervera no olvida la contribución de otros profesores como Federico Torralba o Carmen GarcíaOrmaechea, pero lo que resulta también interesante es constatar el reconocimiento que se hace a una nueva historia del arte asiático que se vislumbra a partir de los replanteamientos epistemológicos que abre la crisis postmoderna. Con todo, echamos en falta en este estudio una mayor atención al fenómeno expansivo del arte chino e indio de las últimas décadas, cuya repercusión en el mundo expositivo y en el mercado artístico parece fuera de toda duda.

La reflexión que nos propone María Rosón sobre la historia de la fotografía en España va más allá del reconocimiento de una mera relación de autores y libros y se adentra en lo que supone una revisión historiográfica que no oculta incluso alguna crítica explícita. Desde luego, nadie niega la importancia de los relatos históricos de autores como Lee Fontanella o Publio López Mondéjar, que mejoran con mucho la discretísima aportación aparecida en la Historia de la fotografía de Marie-Loup Sougez de los años ochenta, autora que luego coordi- 
nará una obra posterior con importante presencia española. Al referirse al texto coordinado por Sánchez Vigil en la conocida colección Summa Artis, Rosón discrepa del punto de vista que se manifiesta en el texto de Joan Fontcuberta, pues prescinde este de campos amplios de la difusión fotográfica, como la prensa o el mundo de la vida cotidiana, y se centra exclusivamente en lo que él entiende que es la pura dimensión artística de la fotografía. Debe relacionarse esta crítica en sintonía con la reconsideración de la importancia de las fotografías personales y la tendencia creciente a integrar los estudios sobre fotografía en el área más amplia de la cultura visual, cuyas posibilidades han permitido una diversidad de interpretaciones que abarcan tanto lo político como lo cultural y lo social.

Aunque ubicado en un apartado diferente en el libro, el texto de Álvaro Molina sobre la significación del siglo XVIII en la historia del arte español debe relacionarse con los ya mencionados de Jesusa Vega o Javier Portús. Señala Molina con bastante apoyo bibliográfico la excepcionalidad que supone la valoración del siglo XVIII en el contexto historiográfico español, una excepcionalidad que se explica por el distanciamiento con el que una gran cantidad de autores del siglo XIX y XX han querido valorar unas aportaciones artísticas consideradas en gran medida alejadas de una raíz esencialmente española y más bien influidas por el gusto francés dominante en ese periodo. Se trata por tanto, de un prejuicio del que solamente se salvan algunos artistas, especialmente Goya, sobre todo por lo que tiene este de identificación con esos supuestos valores raciales exaltados por la sensibilidad romántica. Como apunta el autor de este capítulo, el mismo Menéndez Pelayo incidió, en su Historia de las ideas estéticas, en esta valoración negativa del siglo de la Ilustración, valorado por él con indudable displicencia. Es cierto, por otra parte, que el propio Ortega o Marañón iniciaron una revisión de estas interpretaciones, pero en un tramo importante del siglo XX contamos con aportaciones reincidentes de historiadores influido por el franquismo ideológico, como Pompey, José María Junoy o incluso Chueca Goitia, reflexiones que se ven contrarrestadas por otras de autores como Gaya Nuño o Sánchez Cantón. En cualquier caso, como bien señala Molina, habrá que esperar a una historia del arte más reciente (Carlos Sambricio, Jesús Urrea, Juan José Luna, José Luis Morales y Marín, Rogelio Buendía y Miguel Morán Turina) para ver confirmada esta revisión, que en los últimos años se ha visto ampliada en el marco de la crisis epistemológica que afecta a las disciplinas humanísticas y a la historia del arte tradicional y se abre a la versatilidad que proponen los estudios visuales.

Sobre dos críticos del siglo XX muy significados ideológicamente, Moreno Galván y Valeriano Bozal, trata el capítulo escrito por Noemí Haro. Quiere esta autora contextualizar la contribución de ambos críticos, que arranca en la década de los sesenta, un momento en el que se consolida una renovación metodológica influida en gran medida por el marxismo y de la que se hacen eco no solamente los citados, sino otros como Aguilera Cerni, Cirici Pellicer y Giménez Pericás. En todos ellos se observa el deseo de superar el esteticismo formalista y ahondar en las relaciones entre arte y sociedad. Siendo estos dos críticos de perfiles biográficos no exactamente coincidentes, sin embargo, algunas vicisitudes vividas en el franquismo pueden considerarse experiencias compartidas, especialmente en lo que se refiere al papel de la censura, destacado aquí de manera muy pertinente, pues Haro acude a los informes de los censores para documentar aquellos aspectos más controvertidos para el franquismo de la labor de ambos. Por otro lado, en el caso de Moreno Galván no solamente se destaca la 
significación de su actividad intelectual con la referencia de sus principales obras, también algunas claves de estas, como la reivindicación que hace de la modernidad española en un libro tan sugerente como es la Introducción a la pintura española actual. La autora presta atención también a un texto relevante del crítico andaluz como fue su Autocrítica del arte, si bien no nos parece que su análisis agote el total de sugerencias que este compendio de críticas propone. En Valeriano Bozal, la aproximación a su trayectoria inicial, señalada por dos textos claves sobre el realismo publicados en los sesenta, permite profundizar en la importancia de las fuentes utilizadas por el crítico, que abarcan un amplio abanico que va de Hegel a Galvano della Volpe, algo que demuestra hasta qué punto se está procediendo en estos momento a una renovación de la crítica que rompe claramente con las inercias del pasado, aun en pleno franquismo. De la extensa bibliografía posterior de Bozal, Haro destaca especialmente la significación historiográfica de la Historia del arte en España, un libro cuya aparición en los setenta se quiere subrayar como un acontecimiento relevante.

El arte español del siglo XIX y su visibilidad en el Museo del Prado es el tema elegido por Isabel Tejada Martín en este libro. Con independencia de las vicisitudes que esta colección ha sufrido a lo largo de la historia de la principal pinacoteca española, a la autora le interesa señalar también la enorme importancia que a su juicio ha tenido la renovación museográfica internacional respecto a las obras de este periodo, cuya valoración se ha visto muy condicionadas por los viejos prejuicios basados en la visión moderna que distinguía de forma tajante entre arte rupturista antiacadémico y arte académico. En este sentido, la mirada museográfica renovada que se inicia en la segunda mitad de los ochenta en el Musee d'Orsay de París daba por superado este paradigma y abría una nueva perspectiva de la que no puede ser ajena el Prado. Subraya Tejada que el arte español del siglo XIX, desde una perspectiva histórica, se ve condicionado por la importancia que nuestra historiografía ha dado a la pintura del XVII y el protagonismo incuestionable de Goya como precursor de la modernidad, lo que sitúa a las colecciones del XIX en un espacio intermedio cuyo significado no siempre ofrece una interpretación sencilla. Lo que hoy se puede ver en el Museo del Prado del siglo XIX, fruto de la remodelación de 2009, es un repertorio estimable que recorre dieciséis salas de la pinacoteca y que, sin embargo no está exenta de consideraciones críticas. Apunta con acierto la autora a este respecto el desinterés por la producción de las colonias americana o de las artistas mujeres; también la exclusión del grabado y la fotografía.

Un estudio sobre el alcance historiográfico del proyecto «Desacuerdos» en el ámbito del arte español, escrito por Iñaki Estella Noriega, cierra el conjunto de textos de esta obra colectiva. A través de sucesivas exposiciones y la consiguiente edición de cuadernos se va definiendo el perfil crítico de este proyecto de investigación, iniciado en 2003, no exento de apoyos institucionales de importancia como son el MACBA, Arteleku, el Centro José Guerrero-Diputación de Granada y la Universidad Internacional de Andalucía. Como señala Estella, este perfil crítico y alternativo, en sintonía con planteamientos rupturistas del momento como los expuestos por Mar Villaespesa o Eduardo Subirats, se define por su claro enfrentamiento al sistema arte que se había generado y consolidado en el marco de la transición política española. Esto suponía discrepar de las narrativas que desde ese contexto se habían elaborado sobre la significación del arte español contemporáneo, muy vinculado a los «éxitos» de la nueva política expositiva y los proyectos museográficos desarrollados por los gobiernos 
del periodo democrático. Saltaban aquí también las referencias a la feria ARCO y al boom de la pintura de los ochenta, Algunos nombres, como el del profesor Jesús Carrillo, son mencionados por su importancia como dinamizadores del proyecto, pero entre ellos, sin duda brilla el artista Marcelo Expósito, creador del proyecto de investigación titulado «1969... Algunas hipótesis de ruptura para una historia política del arte en el Estado español», verdadero punto de arranque de «Desacuerdos». Le interesa además al autor destacar la importancia que el proyecto ha tenido para una reconsideración de nuevos criterios museográficos que rompan con el autismo del espacio sagrado expositor y se abra a las inquietudes sociales a través de iniciativas educativas. Cabe preguntarse, en todo caso, si queremos evitar una explicación en clave demasiado optimista, hasta qué punto las propuestas de proyectos como «Desacuerdo» han sido capaces realmente de alterar las líneas dominantes en la interpretación de la historia del arte español contemporáneo. Dicho de otra manera, ¿cuáles pueden ser los límites de una iniciativa de estas característica en el contexto complejo de la cultura artística española contemporánea? La respuesta no es fácil, desde luego. 